\title{
Let us ask better questions
}

\author{
Ellen Wright Clayton, MD, JD ${ }^{1}$ and Susan E. Kelly, PhD²
}

Ramoni et al. ${ }^{1}$ is the latest in a recent series of papers ${ }^{2-4}$ reporting the results of surveys and interviews with researchers exploring their views about return of results. The debate about returning the results of genomics research has been heated, including in this journal, but we argue here that results of surveys of investigators have little value in policy formation about this issue. We need to ask better questions.

Given that a primary justification for returning research results is to improve participants' outcomes by reducing disease risk, ${ }^{5,6}$ ethics research undertaken to inform this debate must engage health policy. What matters for policy formation-and what we need evidence about-is what people actually do. Yet it is commonplace to observe a wide gap between what people say they will do or would like to do and their ultimate actions. The results here are no different. Ramoni et al. found that although two-thirds of the investigators they surveyed thought that return of research results was warranted under at least some circumstances, $<10 \%$ had actually returned results, observations similar to those reported by others. The first Electronic Medical Records and Genomics (eMERGE) consortium, for example, returned no results, despite extensive discussion about which results to return. ${ }^{7}$

The fact that there is such a gap between survey responses and actions raises a fundamental question about what these surveys and interviews, which typically pose hypothetical questions to researchers whose connections with research participants range from clinician scientists and primary data gatherers to downstream data users, actually reveal. The research may simply be accessing idealized expressions of how the researcher respondents would prefer to act, unconstrained by resources and the attitudes and actions of others. But even if one were to take these responses as probative of investigators' attitudes, these studies are not getting at what actually drives action, nor about the circumstances encountered in the conduct of research that lead to the disconnect between stated attitudes and outcomes. For example, although Ramoni et al. seek to identify which responses distinguished those researchers who report believing that results should be returned from those who do not, they do not answer the question of how salient any of these responses are or have been in determining whether or not results were returned. An understanding of what conditions-and to what extent attitudes and whose-drive action in the conduct of research would provide more useful evidence for debate. That is, we need an understanding of how the conduct and contexts of research mitigate for or against actions such as the return of results.

Regardless of the relationship between opinion and action, the question still remains of what weight researchers' views should be given. The issue is both as broad as the value of surveys and responses to hypothetical questions and scenarios in producing evidence about how the world is and should be, and as narrow as how or whether to make the leap from attitudes of researchers to an ethical imperative to return or not return results. In what sense, if any, is it accurate to say that "genome investigators are critical stakeholders in this debate"? The conditions of their work will be shaped by the outcome of this discussion, but ultimately, researchers are not the ones whose lives will be transformed, for good or for ill, by getting information about their genetic makeup. Moreover, it would be peculiar to conclude that alleviating researchers' moral unease is sufficient to justify returning research results in light of the moral discomfort that pervades the lives of clinicians, patients, and their families.

Ultimately, learning more about what investigators think and do is simply less important from a policy perspective than what returning genomic research results will mean for an array of other people and institutions. Much more needs to be known about the impact of returning research results or not on the lives of research participants. We need to know whether returning research results actually leads to better outcomes for participants or whether it causes undesirable distress, results that are as yet unknown. Much of the research to date has been encouraging, particularly with regard to returning results pertinent to the particular clinical problem that was the focus of research, ${ }^{8}$ but less is known about the impact of receiving incidental findings, particularly given the frequent difficulties in their interpretation.

Examining the impact of returning results on the health-care system more broadly is critical. It is naive to argue that returning these results will not increase health-care costs-increasing surveillance and intervention is often the justification for return-but we need to ask whether the outcomes justify the expenditures. ${ }^{9}$ These costs include the impact of returning genomic research results on health-care providers and

${ }^{1}$ Center for Biomedical Ethics and Society, Vanderbilt University, Nashville, Tennessee, USA; ${ }^{2}$ ESRC Centre for Genomics in Society, University of Exeter, Exeter, UK.

Correspondence: Ellen Wright Clayton (ellen.clayton@vanderbilt.edu) 
the health-care system more generally, including opportunity costs, because returning research results will surely alter the flow of clinical work, perhaps impeding other, more effective care. Assessing the impact of returning research results on outcomes for participants and health systems is a moral imperative.

We also need to know how a practice of returning research results will affect the research enterprise. There can be no denying that this will be costly; some of the proposed mechanisms for returning results are enormously complex. ${ }^{10}$ But it is important to ask whether the purported benefits of returning results, ranging from improved health-care outcomes to enhancing participant trust, are actually worth the costs, particularly if it diverts resources from research that will help future patients. ${ }^{11}$ Cost must be taken into account in ethical analysis, especially because returning research results is not a moral absolute.

We need to define who the stakeholders are and the salience of their various positions and actions for specific policy and bioethical deliberations. Investigators' opinions of the sort reported here and by others are of limited relevance to the big issues. Let us ask better questions, including examining the impact of returning research results on participants, health care, and the research enterprise, and let us ask them of the respondents who can provide the answers we need. Let us have a debate about the types of evidence that will meaningfully inform policy and fund the research required to obtain it.

\section{ACKNOWLEDGMENT}

This commentary was funded in part by grant 1R21HG00612-01.

\section{DISCLOSURE}

The authors declare no conflict of interest.

\section{REFERENCES}

1. Ramoni RB, McGuire AL, Robinson JO, Morley DS, Plon SE, Joffe S. Experiences and attitudes of genome investigators regarding return of individual genetic test results. Genet Med 2013;15:882-887.

2. Meacham MC, Starks H, Burke W, Edwards K. Researcher perspectives on disclosure of incidental findings in genetic research. J Empir Res Hum Res Ethics 2010;5:31-41.

3. Williams JK, Daack-Hirsch S, Driessnack M, et al. Researcher and institutional review board chair perspectives on incidental findings in genomic research. Genet Test Mol Biomarkers 2012;16:508-513.

4. Heaney C, Tindall G, Lucas J, Haga SB. Researcher practices on returning genetic research results. Genet Test Mol Biomarkers 2010;14:821-827.

5. Wolf $\mathrm{SM}$, Lawrenz FP, Nelson CA, et al. Managing incidental findings in human subjects research: analysis and recommendations. J Law Med Ethics: I Am Soc Law Med Ethics Summer 2008;36(2):219-248, 211.

6. Fabsitz RR, McGuire A, Sharp RR, et al. Ethical and practical guidelines for reporting genetic research results to study participants: updated guidelines from a National Heart, Lung, and Blood Institute working group. Circ Cardiovasc Genet 2010;3(6):574-580.

7. Fullerton $S M$, Wolf WA, Brothers KB, et al. Return of individual research results from genome-wide association studies: experience of the Electronic Medical Records and Genomics (eMERGE) Network. Genet Med 2012;14:424-431.

8. Ashida S, Koehly LM, Roberts JS, Chen CA, Hiraki S, Green RC. The role of disease perceptions and results sharing in psychological adaptation after genetic susceptibility testing: the REVEAL Study. Eur J Hum Genet 2010;18:1296-1301.

9. Roundtable on Translating Genomic-Based Research for Health, Board on Health Sciences Policy, Institute of Medicine. Assessing the Economics of Genomic Medicine: A Workshop. National Academy Press: Washington, D.C., 2012.

10. Wolf SM, Crock BN, Van Ness B, et al. Managing incidental findings and research results in genomic research involving biobanks and archived data sets. Genet Med 2012;14:361-384.

11. Bledsoe MJ, Clayton EW, McGuire AL, Grizzle WE, O'Rourke PP, Zeps N. Return of research results from genomic biobanks: cost matters. Genet Med 2013;15:103-105. 